\title{
Criteria for assessing a client's fitness for admission to a welfare home: a practical proposition
}

\author{
GORDON KEITH WILCOCK AND MARILYN WILTSHIRE \\ From the Department of Geriatric Medicine, Radcliffe Infirmary, Oxford OX2 6HE, UK
}

SUMMARY A study of the residents admitted to five Oxfordshire old people's welfare homes was undertaken to discover whether it was possible to define criteria that could be used by workers in different professional fields when assessing the suitability of an elderly person for welfare home accommodation. It is possible to produce useful and practical guidelines using the physical disability subsection of the Stockton Geriatric Rating Scale, as well as the overall score, but it is probably necessary for each area to assess its own cut-off points. The use of cut-off points was, from a practical point of view, as effective as and easier than using individual items on the rating scale as a means of discriminating between those suitable for welfare home accommodation and other clients who are unsuitable.

The role of local authority welfare home accommodation (part III accommodation) in the care of the elderly has never been clearly defined. In consequence, medical staff and field and residential social workers often disagree over what constitutes suitability for this type of 'care. Part III fitness is a broad concept involving more than an assessment of the individual applicant. As Roe and Guillem ${ }^{1}$ pointed out, other factors such as the number and attitudes of staff, the overall disability level in the home, and even its architecture are all relevent when suitability of individuals for admission is being discussed.

In Oxfordshire, as elsewhere, the lack of standardised admission criteria means that assessment of fitness tends to be a subjective judgment, and so may vary between old people's homes and within individual homes at different times. When preparing patients for admission to a welfare home from hospital it is often difficult to gauge their suitability even in terms of their basic physical and mental state.

The aim of this study was to investigate the possibility of defining criteria that might help in making the assessment of fitness more objective, so that those in different disciplines might have a similar concept of what constituted fitness. The method used is sufficiently flexible to be applicable in different areas with their varying requirements.

\section{Method}

The Stockton Geriatric Rating Scale (SGRS) ${ }^{2}$ was used as a method of assessment. The scale measures four areas of impairment-physical disability, apathy, communication difficulties, and social disturbance-and the combined score for the four subsections provides an overall measure of behavioural disability. Sensory impairments are also rated but do not contribute to the total score.

The study took place in five Oxfordshire old people's homes. A senior staff member in each home completed the SGRS for the permanent population (198 residents in the five homes) and indicated which residents were considered fit, which borderline, and which unfit at that time. The same procedure was followed for 62 sequential new permanent admissions to the homes shortly after permanent admission was confirmed.

Discriminant function analyses were applied to the SGRS total, four subscores, and the individual items on the scale to see if it was possible to identify any pattern of disability common to all residents who were considered to be part III fit, and whether there were any items that effectively separated them from residents who were considered to be inappropriately placed. In view of the comparatively small numbers of borderline and unfit residents a three-way analysis was inappropriate, and these two groups were 
combined to form a group of 70 "others" in contrast to the 190 "correctly placed" residents.

\section{Results}

Altogether 190 residents were considered fit, 45 borderline, and 25 unfit. These assessments were made independently by the residential home staff and a "medical team" consisting of a consultant geriatrician and a research assistant, formerly a medical social worker. The broad measure of agreement obtained by these two approaches is summarised in table 1 . There were 179 women and 81 men with an age range of 57 to 100 years (mean 81.4 ) and the duration of stay ranged from two weeks to 21 years.

\section{SGRS SCORES}

The scores indicating those residents most likely to be fit enough for welfare home accommodation were found to be:

(a) up to five for the physical disability section,

(b) up to six for the apathy section,

(c) up to two for the social disturbance section, and

(d) up to 13 on the total SGRS score.

Any impairment of communication was associated with a resident who was unlikely to be considered fit for this type of accommodation.

Table 2 shows the percentages of residents correctly classified using each of these scores. The cut-off points of physical disability and the total SGRS score identified roughly $90 \%$ of the residents considered fit and appropriately placed. For the

Table 1 Interdisciplinary assessments of part III fitness

\begin{tabular}{llllll}
\hline & \multicolumn{4}{c}{ Medical team } \\
\cline { 3 - 6 } & & Part III fit & Borderline & Unfit & Total \\
\hline Residential & Part III fit & 165 & 13 & 12 & 190 \\
staff & Borderline & 7 & 16 & 22 & 45 \\
& Unfit & 0 & 0 & 25 & 25 \\
& Total & 172 & 29 & 59 & 260 \\
\hline
\end{tabular}

Table 2 Use of SGRS score and subscores in classifying residents as suitable or unsuitable for welfare home accommodation

\begin{tabular}{|c|c|}
\hline & Percentage correctly classified as fit \\
\hline $\begin{array}{l}\text { Physical disability: } \\
\text { Score of } 5 \text { or fewer }\end{array}$ & 91 \\
\hline Apathy: & \\
\hline $\begin{array}{l}\text { Score of } 6 \text { or fewer } \\
\text { Communication difficulties: }\end{array}$ & 77 \\
\hline $\begin{array}{l}\text { Score of } 0 \\
\text { Social disturbance: }\end{array}$ & 84 \\
\hline Score of 2 or fewer & 83 \\
\hline $\begin{array}{l}\text { Total score: } \\
\text { Score of } 13 \text { or fewer }\end{array}$ & 88 \\
\hline
\end{tabular}

group as a whole there was a high correlation between these two scores with a correlation coefficient of $0 \cdot 87$. The other three sections were not such effective discriminants.

The cut-off scores for physical disability and SGRS total score were' applied to 47 further potential residents being considered for admission to the five homes participating in the study after the staff assessment had been completed and without knowledge of the outcome. Using the cut-off point of 13 or fewer on the total SGRS score we classified 34 residents as fit for welfare home accommodation, of whom 33 had already been accepted as appropriate for placement by the staff. A cut-off point of five or fewer on the physical disability score classified 32 residents as fit, as opposed to 33. Again there was a high correlation coefficient $(0.92)$ between the score in the physical disability section and the total score for the SGRS as a whole.

\section{USE OF INDIVIDUAL SGRS ITEMS}

Ten of the SGRS items discriminated between those residents considered fit and the others. These are shown in step-wise order in table 3 in decreasing order of significance. For the purpose of this analysis, scores for bathing and dressing were recorded separately and eyesight and hearing were included as potentially important items. The items shown in table 3 , taken in combination, correctly classified $90 \%$ of residents overall and the percentage of correct classification was high in both groups-that is, $91 \%$ for those considered fit for welfare home accommodation and $86 \%$ of those considered unsuitable.

A similar result was obtained when this method was applied to the 47 subsequent admissions, as only $5 \%$ were allocated to a different group when their performance on individual items was considered.

\section{Discussion}

The SGRS was used in this study as high correlations have been found between the subscores and total

Table 3 Stepwise order of SGRS items discriminating between fit and unfit residents

\begin{tabular}{llc}
\hline SGRS item & $\begin{array}{c}\text { Discriminant function } \\
\text { coefficient }\end{array}$ \\
\hline 1 & Dressing & 0.42756 \\
3 & Incontinence & 0.43131 \\
6 & Untidy appearance & 0.31895 \\
7 & Needs supervision outside & 0.15440 \\
11 & Goes along with requests & 0.20717 \\
17 & Hoards trivia & -0.14577 \\
14 & Objectionable behaviour during day & 0.12572 \\
2 & Walking & -0.11164 \\
9 & Keeps self occupied & 0.08832 \\
4 & In bed during day & -0.17856 \\
& Constant & -1.12246 \\
\hline
\end{tabular}


score, and the SGRS as a whole is capable of differentiating different degrees of disability in the same environment. ${ }^{2}$

Although there was considerable agreement between the assessments made by the residential home staff and the medical "team," surprisingly many discrepancies arose because the medical assessment was the more stringent, classifying as unfit or borderline 25 of those accepted as part III fit by the staff in the residential homes (table 1). The reverse is often considered to be the case.

The results suggest that in the five homes studied a score of up to 13 points in total, or up to five on the physical disability subsections, would correctly classify most part III fit residents. This method is simple and flexible and could easily be applied in different areas, or in the same area at different times, and facilitate the assessment of a potential resident's suitability for welfare home accommodation. Nevertheless, those in the different disciplines concerned would have to agree, and review from time to time if appropriate, the specific level of cut-off for part III fitness, perhaps through consideration by the local joint care planning team for the elderly. Pattie and Gilleard ${ }^{3}$ suggested that a preadmission score of seven or fewer on the SGRS could identify about $81 \%$ of residents likely to show "high adjustment-minimal deterioration" over the first year after admission. In our study, however, a cut-off point of seven on the total SGRS score identified only $49 \%$ of those considered by the staff to be fit for welfare home accommodation. Masterton $\mathrm{et}^{\mathrm{al}}{ }^{4}$ also found a cut-off point of seven too stringent. The variation in these findings probably confirms local differences in what constitutes part III fitness, and indicates a need for each area to set its own limits. Our study shows that this is possible and is a practical proposition.

The method using individual SGRS items has little advantage over that using the cut-off points mentioned previously and is more cumbersome to apply-for instance, it means calculating the unstandardised discriminant function coefficient for each item, as well as the other mathematical complexities. It is probably of theoretical rather than practical value in the day-to-day setting.*

It is surprising how well this model worked when you consider the potential sources of error necessarily inherent in a study of this kind, including the variability of assessment criteria between staff in different homes, and the subjectivity of the assessment of fitness made by the staff in the absence of definitive guidelines. Once the latter are established, however, all who decide whether or not a potential resident is suitable for welfare home accommodation would have the same criteria to apply. This should also increase the confidence of one group of workers in the decision made by colleagues in a different discipline-for instance, between those working in social services and the NHS.

We thank Oxfordshire County Council Social Services Department, in particular Mr J Llewellyn, director, Mr R Norrie, assistant director, and the heads and staff of the homes concerned. We are also grateful for the statistical advice given by Dr A Barr and Mr J Ennis (Statistics Department, Oxford Regional Health Authority). This study was part of a project supported by a grant from the Oxford Regional Health Authority.

*Full details of this method may be obtained from the authors if required.

\section{References}

${ }^{1}$ Roe PF, Guillem VL. Medical screening of part III residents in Somerset. Health and Social Services Journal 1978; 88: 168-9.

${ }^{2}$ Pattie AH, Guilleard CJ. Clifton assessment procedures for the elderly. Sevenoaks: Hodder and Stoughton Educational, 1979.

${ }^{3}$ Pattie AH, Gilleard CJ. Admission and adjustment of residents in homes for the elderly. $J$ Epidemiol Community Health 1978; 32: 212-4.

4Masterton G, Holloway EM, Timbury GC. The behavioural characteristics of local authority home residents referred to a geriatric psychiatry service. $J$ Epidemiol Community Health 1980; 34: 102-5. 